\title{
DHARMA YUDHA KARMA \\ DALAM KITAB SUCI BHAGAVADGITA
}

\author{
Oleh : \\ Ida Bagus Putu Eka Suadnyana \\ Universitas Hindu Indonesia \\ gusekasuadnyana@unhi.ac.id
}

\begin{abstract}
In the holy book of Bhagawad Gita that is one of Hindu's holy book that assumed as pancamo weda. In the holy bookk of Bhagawad Gita, there are eighteen chapter which is unity that in each chapter contents holy teaching that should as guidance in human life. One of lesson that written in the holy book is Dharma Yudha Karma that written at chapter II that is Samkhya yoga? At this lesson assumed important explored its existence and how is the form of this lesson. There are some function of lesson of Dharma Yuda Karma that are spiritual function and improvement on life quality through incline of spiritual that have important position in the society. There are some education value that contents inside as follows ethic education value, ritual education value and tattwa education value that taken from Hindu's doctrine self.
\end{abstract}

Keywords: Dharma Yudha Karma, Hindu, Bhagavadgita

\section{A. PENDAhuluan}

Sumber sastra suci tertinggi bagi umat disebut sebagai Weda. Weda sebagai kitab suci umat Hindu terbagi atas dua bagian yaitu Sruti dan Smerti. Weda ini dikenal pula oleh para umat yang disebut Catur Weda, disamping itu ada pula yang disebut sebagai Weda kelima atau Pancama Weda, yaitu Bhagawad Gita. Sebagai Weda kelima kitab suci Bhagawad Gita dari kitab Mahabharata, sehingga dapat disimpulkan bahwa Kitab Bhagawad Gita bagian terkecil dari Weda, Kitab suci Bhagawad Gita berisikan bagian dari kisah Bhisma Parwa dari epos besar Mahabharata.
Pentingnya kitab suci Bhagawad Gita karena isinya merupakan ajaran puncak agama Hindu yang secara umum sebagai suatu suplemen dalam mempelajari kitab suci Catur Weda atau Weda Sruti (Pudja, 1978 :123).

Secara struktural isi kitab suci Bhagawad Gita lebih terarah dan merupakan pengejawantahan dari Weda-Weda sebelumnya, hal ini terbukti sebagaimana halnya di sebutkan dalam PuranaPurana bahwa usaha-usaha mengkodifikasi Catur Weda sebagai jasa besar dari Bhagawan Abyasa (Wyasa) yang tampaknya Bhagawad Gita pun 
merupakan gubahan beliau. Usaha ini merupakan langkah perkembangan sejarah pikiran dari agama Hindu. Dijelaskan dalam ajaran agama Hindu tujuan hidup manusia terakhir adalah "Moksa" di samping itu pula bagi umatnya diajarkan agar selalu berbuat baik dan berbhakti kepada Tuhan Yang Maha Esa, serta bertanggung jawab atas pembangunan bangsa dan negara.

Memperhatikan kedudukan kitab suci Bhagawad Gita di antara kitab-kitab Weda lainnya, maka sangat perlu pemahaman terhadap ajaranajarannya dilakukan dengan sungguh-sungguh, karena banyak mengandung nilai-nilai kehidupan beragama, di samping itu pula kitab Suci Bhagawad Gita banyak mengandung ajaran-ajaran spiritual yang sangat bermanfaat bagi umat Hindu. Adapun isi dari Bhagawad Gita terdiri dari $18 \mathrm{Bab}$, dari kedelapan belas bab bhagawad gita tesebut sangatlah kental akan ajaran-ajaran kerohanian yang tidak hanya melingkapi kehidupan spiritual semata, namun juga mengarahkan manusia untuk mengendalikan keinginan duniawi dengan perantara kerja tanpa mengharapkan hasil.

Pada hakekatnya pencerminan dari ajaran Dharma Yudha Karma tercermin dalam kitab Suci Bhagawad Gita Bab III yaitu dalam Karma Yoga yang menguraikan hakekat karma sebagai kehidupan aktif yang belandaskan kerja tanpa terikat dengan hasil. Krisna memberikan jawaban tentang tindakan atau kerja adalah hukum alam. Bekerja seperti yang telah diwajibkan dengan kebhaktian dan pengabdian kepada Brahma, tanpa mengharapkan keuntungan pribadi tentang tindakan. Dalam hal ini perwujudan tindakan atau karma dapat dibedakan ke dalam dua bentuk yaitu pertama Subha Karma yaitu perbuatan yang baik dan kedua Asubha Karma yaitu perbuatan yang tidak baik. Dengan melihat hal tersebut diatas, maka dapatlah dua pengertian kata karma yang berkembang dalam Bhagawad Gita yaitu : karma dalam arti yadnya, dan kedua, karma dalam arti tingkah laku atau perbuatan Ajaran dharma yudha karma adalah satu ajaran yang didasarkan akan karma atau kerja. Itu tercermin dalam bentuk kerja dalam melaksanakan perang yang mana perang tidak secara harfiah semata namun juga kerja dalam bentuk berperang dan mengendalikan sifat maya dalam tubuh ini.

Dalam ajaran Dharma Yudha Karma mengacu ke dalam Bab II Samkhya Yoga, “Ajaran Samkhya Yoga adalah ajaran yang monodualistis, yaitu ajaran tentang purusa dan prakerti yang berasal dari Tuhan (Iswara). Seperti yang dicantumkan pada bab II yaitu Samkhya Yoga, dengan timbulnya keragu-raguan pada diri Arjuna, maka Krisna memberikan tanggapan dengan menyatakan bahwa konflik pribadi yang terjadi pada setiap manusia dan hakekatnya bersumber pada beberapa sebab, pertama, sifat putus asa yang ada pada diri manusia yang menyebabkan manusia menyerahkan pada keadaan. Sifat lemah inilah yang bertentangan dengan ajaran agama Hindu yang diwajibkan agar tidak berputus asa dalam segala hal dan kedua, kebodohan kesalah pahaman tentang ajaran dan kenyataan. Demikian pula masalah pencapaian tujuan yang terakhir disebut dengan moksa, bersumber pada kesalahpahaman. Dengan kesalahpahaman pada diri Arjuna itu, maka Krisna mencoba menjelaskan hakikat hidup dan tujuan hidup yang sebenarnya, sebagaimana yang telah diajarkan dalam agama Hindu. 
Ajaran dharma yudha karma yang bersumber dari kitab suci Bhagawad Gita sangatlah menarik untuk dikaji, karena bukan hanya menggali bagaimana kewajiban dalam bentuk perang semata tetapi menyimpan banyak ajaran-ajaran rohani yang sangat luhur. Ini tercermin dalam kitab suci bhagawad gita bab II Samkhya Yoga. Karma sebagai hukum alam dilaksanakan dalam bentuk kerja didalam kehidupan yang aktif.

\section{B. PEMBAHASAN}

1. Ajaran Dharma Yudha Karma

Dalam Kitab Suci Bhagawad Gita mengandung ajaran-ajaran perjuangan dalam menegakkan Dharma. Pada mulanya seorang tokoh yang bernama Arjuna dalam medan perang mereka mempunyai sifat ragu-ragu karena yang dihadapinya adalah saudara-saudaranya para Korawa dan ada pula paman, guru, ipar sepupu, cucu, kawan dan sahabat-sahabatnnya yang lain. Atas dasar itulah Arjuna dengan perasaan yang sangat sedih dan penuh kebimbangan yang bergejolak dalam hatinya yaitu bertempur atau tidak. Kebimbangan dan keragu-raguan itu bukan karena rasa takut, melainkan karena dirinya diikat oleh rasa cinta kasih yang mendalam terhadap mereka sekalian, seperti tercermin dalam Kitab Suci Bhagawad Gita Bab I sloka 28, 29 sebagai berikut :

\footnotetext{
Kripaya paraya vishto, vishidana idam abravit, Arjuna uvacha, drishtvo mam svajanam Krishna, yuyutsum samupasthitam,
}

Sidhanti mama gatrani, mukham cha parisushyati,

vepathus cha sarire me, romaharshas cha jayate.

\section{Terjemahannya :}

Dengan penuh diliputi nestapa, disampaikan rasa duka, Arjuna berkata :

Menyaksikan sanak kadang, Oh Krisna, berbaris siap untuk berlaga.

Anggota bbadanku terasa lemas, mulutku terasa kering,

Sekujur badanku gemetar, dan bulu romanku pada berdiri (S. Pendit, 1996 : 21-22).

Dengan keluh kesah Sang Arjuna memberikan gambaran betapa lemah hatinya, serta kasih sayangnya, sehingga busur dan panah yang dipegangnya jatuh, ia lebih baik mati dari pada bertempur melawan sanak keluarganya, serta para guru, menurutnya tidak ada gunanya kemenangan serta kebahagiaan yang diperoleh dengan jalan membunuh sanak keluarga dan guru. Dalam hal ini Arjuna sangat terikat oleh perasaannya terhadap sanak keluarga, sehingga lupa akan kewajibannya sebagai Ksatria yang bertugas dan bertanggung jawab membela nusa dan bangsa dari pengaruh kedurhakaan dan penyelewenganpenyelewengan. Dua hal mendasar yang perlu direnungkan dalam hal ini adalah masalah cinta kasih dan tugas serta kewajiban.

Dalam percakapan Sri Krisna, akan didapati ajaran filsafat yang sangat dalam oleh 
karena itu luasnya pengertian filsafat Sri Krisna yang dapat merangkum banyak pengertian dan tergantung dari sudut mana pengertiannya dengan ajaran Sri Krisna untuk menyadarkan Arjuna. Hal ini bermaksud untuk menghilangkan rasa keterikatan oleh hawa nafsu, rasa kasih sayang terhadap sesuatu yang tidak kekal dan jangan bersifat lemah hati sebagai seorang Ksatria yang bertugas untuk membela keadilan dunia dan ketentraman serta kesejahteraan rakyat. Orangorang yang terikat pada materi-materi duniawi yang bersifat tidak kekal, maka mereka akan sukar untuk mendapatkan kebebasan baik semasih hidup maupun setelah mati, hal ini tercermin dalam Kitab Suci Bhagawad Gita bab II sloka 1, 2, 3 sebagai berikut :

Sanjaya uvacha, tam tatha kripaya vishtam, asurupurnakulekshanam, vishidantam idam vakyam, uacha madusudanah.

Sri Bhagawan uvacha, kutas tva kasmalam idam, visshame samupasthitam, anaryamjustam asvargyam, akirtikaram Arjuna.

Klaibyam ma sma gamah partha, nai tat tvayy upapadyate, kshudram hridayadaurbalyam, tytvo tishtha paramtapa.

\section{Terjemahannya :}

Sanjaya berkata :

kepadanya, yang diliputi rasa belas kasihan, dengan pelupuk mata digenangi air mata, dan rasa remuk rendam dalam hati, Madusudana berkata berkata begini. Jangan biarkan kelemahan itu, Oh Partha, sebab itu tidak sesuai bagimu, enyahkan rasa lemah dan kecut itu, bangkitlah Oh pahlawan jaya (S. Pendit,1996 : 36-37).

Ajaran Sri krisna kepada Arjuna menyadarkan bahwa kewajiban sebagai seorang Ksatria hendaknya tidak ragu-ragu lagi untuk melenyapkan semua musuh durhaka, walaupun diantara kesemuanya itu terdiri dari beberapa guru, kerabat dan sanak keluarga, untuk itu bagi Ksatria perlu melenyapkan kesemuanya itu, karena mereka berpijak pada kejahatan, yang patut dihilangkan dari muka bumi ini. Hal ini tercermin dalam Kitab Suci Bhagawad Gita bab II sloka 11, 12 sebagai berikut :

\section{Sribhagavan uvacha aso chyam anvaso chas tvam} prajnavadams cha bhahase gatasun agatasumacha. Naa nuso chanti panditah,

Na tv eva ham jatu na sam, na tvam ne me janadhipah, na chai van a bhavishyamah, sav vayam atah parem.

\section{Terjemahannya :}

Sri Bhagawan berkata :

engkau berduka bagi mereka yang tak patut kau sedihi 
namun engkau bicara tentang budi pekerti orang budiman tidak akan bersedih baik bagi yang hidup maupun yang mati. Tidak pernah ada saat ada dimana aku, engkau dan para raja ini tidak ada dan tidak akan ada saat dimana kita berhenti ada, sekalipun sesudah ini (S. pendit, 1996 : 42-43).

Lebih lanjut ajaran filsafat yang diajarkan oleh Sri Krisna pada Arjuna adalah ajaran filsafat tentang hukum karma dan punarbawa. Karma phala itu adalah penentu dari pada penjelmaan bagi orang yang berbuat jahat (adharma) mereka selalu diliputi kebodohan (awidya) dengan demikian mereka pasti akan mendapatkan penderitaan sebagai akibat dari pada perbuatan jahatnya. Hal ini akan dialami pada penjelasan yang akan datang. Pada hakikatnya penjelmaan adalah penderitaan dan juga merupakan saat untuk menghilangkan penderitaan itu dengan jalan berbuat baik. Dalam berbuat perasaan akan mengalami suka duka, tetapi bagi orang yang bijaksana tidak terkait akan suka duka, duniawi itu. Sebab hal ini dipandang suatu hal yang maya dan tidak kekal adanya. Atas dasar itu diperlukan suatu ketenangan, dengan ketenangan menimbulkan suatu kesucian, dengan kesucian lenyaplah penderitaan suatu keyakinan bahwa pekerjaan yang dihadapi adalah suatu kewajiban dan harus mampu menyelesaikannya, maka sudah barang tentu orang yang bijaksana kewajiban dengan penuh tulus ikhlas dan penuh kesadaran. Konsep ajaran ini tercermin dalam Kitab Suci Bhagawad Gita bab II sloka 14, 15 sebagai berikut ini.

\author{
Matrasparsas tu kaunteya, \\ si to shnaskhaduhkhabaha, \\ samaduhkhamukham dhiram, \\ somritatvaya kalpate.
}

Yan hir na vyathayanty ete, Purusham purus harshabha, Samadhikhasukham dhiram So mritatvaya kalpate

\section{Terjemahannya :}

Hubungan dengan benda jasmaniah.

Oh Arjuna menimbulkan panas dan dingin, senang dan duka dan semua itu datang dan pergi, tidak abadi karenanya pikulah, wahai Kunti Putra

Orang yang tidak tergoyahkan ini

Oh Arjuna, yang tetap dalam duka dan senang yang teguh iman patut hidup kekal abadi (S.Pendit, 1996 : 43-45).

Dengan konsep-konsep ajaran seperti tersebut di atas, Sri Krisna mampu menyadarkan Arjuna sehingga dia bersedia untuk berperang, menunaikan tugasnya dan kewajibannya sebagai seorang Ksatria. Sri Krisna menegaskan bahwa kebenaran adalah suatu yang kekal abadi dan mutlak ada pada Tuhan. Dengan dasar itu perlu berjiwa yang .tegas tekun di dalam melaksanakan kewajiban. Konsep ini tercermin dalam Kitab Suci Bhagawad Gita: bab II sloka 17,18 sebagai berikut ini : 
Avinasi tu tad vidhi,

yena sarwam idam tatam,

vinasam avyayasya sya,

na kaschit kartum arhati

Antavanta ime deha, nityasyo ktah saririnah, anasino prameyasya, tasmad yudhyasva bharata

\section{Terjemahannya :}

Ketahuilah yang melengkapi semua ini tidak dapat dihancurkan tidak seorangpun dapat memusnahkan Dia, yang tidak mengenal kemusnahan.

Badan jasmani yang membungkus dia yang langgeng, tiada terhancurkan dan tiada terbatas akan habis sebab itu bertempurlah, wahai Barata (S.Pendit, 1996 : 45-47).

Mengacu kepada Bab II shamkhya yoga maka terdapat sloka-sloka yang secara langsung memberikan gambaran bagaimana ajaran dharma yudha karma tersebut. Dari 73 sloka yang terdapatdalam Bab II tersebut, 22 sloka diantaranya secara langsung mengajarkan dan menyuruh seorang kesatria untuk menjalankan dharmanya dalam bentuk perang. Sloka-sloka tersebut antara lain :

\section{Bg 2.2}

śrī-bhagavān uvāca

kutas tvā kaśmalam idam

visame samupasthitam anārya-justam asvargyam

akīrti-karam arjuna

\section{terjemahannya :}

sri bhagawan berkata :

pada saat kesulitan seperti ini, dimana kedukaan dan lemah hati datang dan sesungguhnya bukan sifat seorang kesatria, tidak luhur dan memalukan serta menjauhkan diri dari orang

\section{Bg 2.3}

klaibyam mā sma gamah pārtha

naitat tvayy upapadyate

ksudram hrdaya-daurbalyam

tyaktvottistha paran-tapa

\section{terjemahannya :}

o arjuna, janganlah kau berikan kelemahan itu, sebabitu tidak sesuai bagimu, lenyapkan rasa kelemahan dan takut itu, bangunlah oh pahlawan yang menggetarkan musuh

Bg 2.4

arjuna uvāca

katham bhīsmam aham samkhye

dronam ca madhusūdana

isubhih pratiyotsyāmi

pūjārhāv ari-sūdana

\section{terjemahannya :}

o madhusudana, bagaimana mungkin saya bisa menyerang bhisma, drone dengan panah dalam pertempuran ini, mereka yang patut saya hormati, o kresna dengan panah dalam pertempuran ini, o kresna 
Bg 2.5

gurūn ahatvā hi mahānubhāvān

śreyo bhoktum bhaiksyam apīha loke

hatvārtha-kāmāms tu gurūn ihaiva

bhuñjīya bhogān rudhira-pradigdhān

\section{terjemahannya :}

daripada membunuh guru yang paling mulia di dunia ini akan lebih baik menjadi peminta-minta, walaupun mabuk duniawi, tetapi tetap menjadi guru saya, sedangkan membunuh mereka berarti hidup berlumuran darah

Bg 2.6

na caitad vidmah kataran no gariyo

yad vā jayema yadi vā no jayeyuh

yān eva hatvā na jijīvisāmas

te 'vasthitāh pramukhe dhārtarāstrāh

\section{terjemahannya :}

yang mana lebih menguntungkan kami,tidaklah jelas apakah kami akan menang, membunuh mereka yang tidak kita harapkan untuk hidup, orang-orang itu sekarang berdiri siap didepan kita, keturunan prabhu drestarasta

Bg 2.18

antavanta ime dehā

nityasyoktāh śarīrinah

anāśino 'prameyasya

tasmād yudhyasva bhārata

\section{terjemahannya :}

sesungguhnya raga jiwa ini, langgeng tiada terhancurkan, dan tiada berbatas akhir, karena itu bertempurlah hai arjuna
Bg 2.19

ya enam vetti hantāram

yaś cainam manyate hatam

ubhau tau na vijānīto

nāyam hanti na hanyate

\section{terjemahannya :}

sesungguhnya ia yang memikirkan ini, sebagai pembunuh dan ia yang berpendapat bahwa, ia dapat dibunuh kedua-duanya adalah dungu, karena ini tidak pernah membunuh dan dibunuh

Bg 2.30

dehī nityam avadhyo 'yam

dehe sarvasya bhārata

tasmāt sarvāni bhūtāni

na tvam śocitum arhasi

\section{terjemahannya :}

yang menghuni badan setiap makhluk, semua tidak akan dapat dibunuh, oh bharata karena itu jangan bersedih atas kematian makhluk apapun

\section{Bg 2.31}

sva-dharmam api cāveksya na vikampitum arhasi dharmyād dhi yuddhāc chreyo 'nyat ksatriyasya na vidyate

terjemahannya :

lagipula bertempur menegakkan kebenaran dengan menyadari akan kewajiban masing-masing, engkau tidak boleh 
gentar, bagi kesatria tidak ada kebahagian lahir bathin lebih besar daripada berperang menegakkan kebenaran

Bg 2.33

atha cet tvam imam dharmyam

sangrāmam na karisyasi

tatah sva-dharmam kīrtim ca

hitvā pāpam avāpsyasi

terjemahannya :

akhirnya bila engkau tidak berperang, sebagaimana kewajiban, dengan meninggalkan kewajiban dan kehormatanmu, maka penderitaanlah yang engaku peroleh

\section{$\mathrm{Bg} 2.36$}

avācya-vādāmś ca bahūn

vadisyanti tavāhitāh

nindantas tava sāmarthyam

tato duhkha-taram nu kim

terjemahannya :

mereka yang menentangmu akan melontarkan caci maki, merendahkan kemampuanmu dengan menjelekkan dan menghina kemampuanmu, apakah yang lebih sedih dari itu

\section{Bg 2.37}

hato vā prāpsyasi svargam

jitvā vā bhoksyase mahīm

tasmād uttistha kaunteya

yuddhāya krta-niścayah terjemahannya :

dengan kematian itu engkau memperoleh surge atau kalau menang, engkau akan menikmati kebahagiaan dunia, oleh karena itu bangkitlah o arjuna bulatkan teka untuk berperang

Bg 2.38

sukha-duhkhe same krtvā

lābhālābhau jayājayau

tato yuddhāya yujyasva

naivam pāpam avāpsyasi

terjemahannya :

dengan menyamakan suka dan duka, untung dan rugi, menag dan kalah, siapkanlah dirimu untuk mengahadapi perang itu, engakau tehindar dari dosa (perasaan bersalah)

Bg 2.40

nehābhikrama-nāśo 'sti

pratyavāyo na vidyate

sv-alpam apy asya dharmasya

trāyate mahato bhayāt

terjemahannya :

dalam hal ini tidak ada usaha sia-sia, dan juga tidak ada rintangan yang tak teratasi, walau sedikit dari dharma ini, akan membebaskan dari ketakutan yang besar

Bg 2.45

trai-gunya-visayā vedā

nistrai-gunyo bhavārjuna

nirdvandvo nitya-sattva-stho

niryoga-ksema ātmavān 
terjemahannya :

weda menguraikan tentang tri guna, arjuna, bebaskan dirimu dari padanya, bebaskan diri dari dualisme, pusatka pikranmu pada kebenaran, lepaskan dirimu dari duniawi, bersatu dengan atman

\section{Bg 2.47}

karmany evādhikāras te

mā phalesu kadācana

mā karma-phala-hetur bhūr

mā te sango 'stv akarmani

terjemahannya :

hanya berbuat demi kewajibanmu, tidak hasil perbuatan itu, jangan sekali-kali pahala mejadi motifmu dalam bekerja, jangan pula hanya berdiam diri

\section{Bg 2.56}

duhkhesv anudvigna-manāh

sukhesu vigata-sprhah

vìta-rāga-bhaya-krodhah

sthita-dhīr munir ucyate

terjemahannya :

orang yang tidak sedih dikala duka tidak kegirangan dikala bahagia bebas dari nafsu, takut, amarah ia disebut orang suci

\section{Bg 2.63}

krodhād bhavati sammohah sammohāt smrti-vibhramah smrti-bhramśād buddhi-nāśo buddhi-nāśāt pranaśyati terjemahannya :

dari amarah timbul kebingungan, dari kebingungan hilang ingatan, dari hilang ingatan menghancurkan pikiran, dari kehancuran pikiran ia musnah

\section{Bg 2.71}

vihāya kāmān yah sarvān

pumāmś carati nihsprhah

nirmamo nirahankārah

sa śāntim adhigacchati

terjemahannya :

orang yang membuang semua nafsunya dan melangkah bebas tanpa keinginan bebas dari perasaan "aku" dan "punyaku" ia mencapai kedamaian

\section{Bg 2.72}

esā brāhmī sthitih pārtha nainām prāpya vimuhyati sthitvāsyām anta-kāle 'pi brahma-nirvānam rcchati

terjemahannya :

inilah tingkat kesucian oh parta dia yang telah samapi ditingkat ini, walau maut tiga, tiada bingung lagi dan mencapai nirwana bersatu dengan Brahman (pudja, 2003:2970)

dari sloka-sloka diatas tercermin suatu pengetahuan tentang perang yang harus dilakukan oleh seorang kesatri karena itu merupakan kewajibannya. Perang bagi seorang kesatri adalah 
keharusan karena ketika dia lari dari tanggung jawabnya maka seorang kesatri akan mendapat cacian dan makian. Tubuh yang dibunuh tidak akan menghancurkan sang diri sejati, karena sang diri sejati merupakan atman yang kekal abadi. Sehingga untuk apa bersedih diri terhadap tubuh yang mati itu. Ketika seorang kesatria mengetahui pengetahuan atman ini maka dia akan dapat meneguhkan hatinya untuk menegakkan dharma itu. Jadi walaupun diajarkan tentang kewajiban untuk berperang, konsepsi ajaran dharma yudha karma ini tidak mengajarkan perang yang sembarangan namun perang untuk menegakkan dharma sebagaiaman para pandawa memperjuangkan dharma dan keadilan mereka yang ditindas oleh para korawa.

Dharma yudha karma pada uraian diatas dari beberapa sloka yang sudah dipaparkan terdapat beberapa hal penting terkait dengan ajaran dharma Yudha karma yaitu manusia hidup sebagai seorang individu sebenarnya atman yang merupakan bagian dari Brahman sehingga sifat-sifat dari Brahman terdapat pula dalam atman. Kebimbangan arjuna dalam perang karena ketidak tahuan arjuna tentang bagaimana manusia sebenarnya, dia hanya melihat manusia sebagaimana mata memandangnya namun tidak mengetahui bahwa realitasnya manusia adalah atman yang tak terhancurkan. Sebagai atman tak patut untuk disedihi karena atman itu abadi.

Di lain hal, sri kresna mengajarkan bahwa walaupun atman abadi namun selama dia terikat dengan karma maka atman akan mengalami suatu keadaan siklus lahir yang berulang-ulang sehingga tak patut untuk bersedih dalam sebuah perang karena yang hancur adalah tubuh bukan sang jati diri sejati. Lebih lanjut dalam sloka berikutnya sri krisna menuturkan bahwa dalam melawan musuh tidak perlu ada rasa keragu-raguan karena ketika adharma merajalela maka dharma harus ditegakkan walaupun musuh yang dilawan adalah sanak saudara sendiri. Terkait dengan ajaran dharma yudha karma dapat ditarik suatu analisa terhadap sloka dalam bab II Bhagawad Gita ini yaitu :

pertama sebagai suatu ajaran dalam melakukan kewajiban dalam perang hendaknya seorang individu dapat menyadari bahwa individu yang dia lawan walaupun mati namun yang mati bukanlah dia yang sejati, namun hanya badan wadag atau badan kasar yang membukus sang diri sejati yaitu atman.

Kedua sebagai suatu ajaran perang diajarkan bahwa ketika adharma merajalela, ketika kejahatan menjadi suatu alasan untuk merebut hak orang lain, bhawa keadilan bukanlah suatu hal yang penting lagi maka dharma sabagi kebenaran harus ditegakkan kembali. Karena dharama merupakan pondasi utama dalam mencapai moksah. Bahkan ketika sanak saudara menjadi musuh untuk menegakkan dharma maka seorang harus siap menegakkan kepala dan melawan. Karena saudara yang dilawan tidak akan menghilang dan hancur, mereka hanya pergi mencari tubuh baru untuk dihidupi, karena sang diri sejati bukanlah tubuh ini melainkan atman dari paramatman. Bagaikan manusia yang meninggalkan baju lama yang sudah using untuk menggunakan baju baru begitu 
pula atma yang meninggalkan tubuh lama menuju tubuh baru sesuai putaran karmanya.

Ketiga bahwa ketika atma terbungkus tubuh jasmani maka sang atma akan mengalami yang namanya suka duka dan hal lain namun dia akan tetap tak terhancurkan. Jadi dalam suatu perang untuk apa menangisi tubuh ini, karena ketika dharma harus ditegakkan maka adharma harus dilawan.

\section{Nilai Tattwa dalam Konsep Dharma Yudha}

\section{Karma}

Dalam konsep Dharma Yudha Karma, nilai-nilai tattwa yang terkandung di dalamya adalah suatu konsep ajaran Samkhya Yoga. "Ajaran Samkhya Yoga adalah ajaran yang monodualistis, yaitu ajaran tentang purusa dan prakerti yang berasal dari Tuhan (Iswara). Konsep ini sering disebut dengan konsep dua tambah satu, yaitu purusa dan praketti ang berasal dari Tuhan (iswara)" (Bemet Kempers, 1977 : 68). Kitab suci Bhagawad Gita memuat ketika Sang Arjuna, mengalami keragu-raguan di medan perang yaitu dijelaskan dalam bab II sloka 11-22 berikut ini.

\section{Sri bhagawan nwaca}

asocyan anwasocassiwan

pradnya wadamsca bhahase

na nusosanti pahditah

na twewa, ham jatuna snam

na twam me janadhipah

na caiwa na bhavihsyamah

sarwo wayam atah param

\section{Terjemahannya:}

Yang mulia Sri Krisna bersabda : Engkau Arjuna untuk sesuatu yang tak patut disusahkan, kamu berkata-kata dengan mengucapkan kata-kata yang bijaksana, tetapi orang bijaksana sebenarnya tak patut menyusahkan hal kematian ataupun kehidupan.

Hal kematian dan kehidupan itu sebenarnya tidak ada, bahwa akupun (Krisna) tidak akan selalu ada, maupun engkau (Arjuna) demikian pula Raja-Raja ini ataupun sekalian mahluk ini tidak akan ada untuk selamanya (Pendit, 1996 : 42-43).

Berdasarkan teks sloka diatas, bahwa dalam menunaikan tugas (karma) tidaklah patut menonjolkan perasaan kasih sayang dan sifat enggan apalagi ragu-ragu. Terhadap kepentingan suatu individu alau golongan yang jahat dan durhaka. sebagai ksatrya, pemimpin atau petugas hendaknya mampu mengambil tindakan dan sikap tegas, terhadap siapa saja yang berbuat jahat dan yang mengganggu keamanan orang banyak. Misalnya kalau ternyata telah ada sesuatu kejahatan yang telah terbukti dibuat orang, biar ia golongan apa saja ataupun biar ia majikan, pimpinan dan orang pernah berjasa sekalipun, haruslah ia mendapat hukuman, demi untuk menegakkan keadilan dan ketentraman dunia. Hal ini telah diperjelas pula dalam teks diatas tadi, namun penjelasannya itu adalah suatu filsafat yang harus direnungkan dalam-dalam untuk dapat memetik inti hakekat yang sedalam-dalamnya. 
Untuk melenyapkan perasaan bimbang dan ragu serta perasaan susah yang disebabkan oleh sifat enggan, dalam menunaikan tugas kewajiban masing-masing. Sri Krisna telah menyampaikan kepada Sang Arjuna bahwa pertama-tama harus disadari tentang diri manusia itu sendiri. Manusia pada hakikatnya terdiri dari dua unsur pokok. yaitu jasmani dan rohani, atau sthula sarira dan atman. Atman itu selalu menghendaki kebaikan sedangkan jasmani selalu cenderung kepada perbuatan yang jahat itu, karena jasmani itu dikoordinir oleh hawa nafsu, yang selalu ingin mencari obyek-obyek pemuasnya Atman itu adalah kekal, sedangkan jasmani adalah maya, selalu mengalami lahir dan kematian. Jadi dalam diri manusia itu sebenarnya terdapat dua unsur yang senantiasa bertentangan yang satu dengan yang lainnya. Manusia harus menyadari bahwa hendaknya selalu berusaha agar atmanya lebih berkuasa dari jasmaninya dengan demikian berarti perbuatannya akan cenderung kepada sesuatu kebaikan. Sri Krisna menyadarkan Arjuna agar melaksanakan kewajiban dan tidak merasa raguragu lagi untuk melenyapkan sekalian musuhmusuhnya yang durhaka itu (Korawa), yang walaupun terdiri dari guru, sanak keluarga dan kaum kerabat, karena justru mereka itu berpihak kepada kejahatan yang harus dilenyapkan dari muka bumi ini.

Jadi jelaslah bahwa seorang ksatrya yang menunaikan kewajibannya dalam medan perang segan-segan untuk membunuh dan melenyapkan segala bentuk kedurhakaan. Demikian juga di dalam kitab suci Bhagawad Gita. bab II sloka 1314 disebutkan sebagai berikut ini.
Dehino smin Yatha dehe

kaumaram yauwanam jara

tatha dehantapraptir

diras tatra na muhyati

Matas parsastu kauteya

sitosna sukha duhka dah

agamo payino nitiyas

tamas titiksa swa Bharata

\section{Terjemahannya}

Bahkan seperti penjelasan itu sendiri mengalami masa kanak-kanak, masa muda, masa tua, maka itu ia memerlukan badan dan orang yang

bijaksana tak dapat dikelabui oleh hal itu

Wahai Arjuna (Putra Kunti) hubungan perasaan

menimbulkan akibat panas dingin, senang dan susah,

demunya ini datang datang silih berganti dan pergi tidak kekal adanya

oleh karena itu ia Arjuna bangkitlah (Pendit, 1996:43-44)

Dalam petikan kedua sloka tersebut diatas, kita dapatkan sebagian dari nasehat Sri Krisna kepada Arjuna, bahwa pada hakekatnya, hidup sebagai manusia adalah tidak kekal, melalui masa kecil, masa muda, dan masa tua, serta melalui kelahiran dan kematian. Tetapi sang jiwa tidak mengalami perubahan (kekal), hanya jasad 
(jasmani) yang tidak kekal. Dalam ajaran itu terpendamlah ajaran filsafat kejiwaan yang dalam. Umat hindu percaya akan hukum karena phala dan punarbhawa (penjelmaan kembali). Karma phala adalah penentu dari pada penjelmaan atau tidaknya seseorang Bagi orang yang berbuat jahat (adharma) mereka selalu diliputi oleh kebodohan (awidya), dengan demikian mereka pasti akan mendapat penderitaan sebagai akibat dari karmanya yakni mereka akan mengalami penjelmaan berulangulang. Penjelmaan itu adalah penderitaan dan juga merupakan saat untuk menghilangkan penderitaan itu dengan jalan berbuat baik dan mengutamakan dharma.

Orang hidup ini selalu digoda oleh hawa nafsu dan untuk memenuhi nafsu itu orang berbuat sesuatu. Dalam berbuat itulah mereka akan mengalami perasaan suka dan duka. Namun bagi orang yang bijaksana, mereka itu tidak akan terpengaruh oleh perasaan suka duka itu karena mereka yakin bahwa perasaan suka duka itu adalah bersifat sementara dan maya Hal yang maya ini bagi orang yang bijaksana adalah tidak akan mengikat dirinya, dengan demikian mereka akan selalu tenang walaupun dalam keadaan sedih maupun gembira. Sebab dari ketenangan inilah mereka akan mendapatkan kesucian dan melalui kesucian akan melenyapkan penderitaan dan penjelmaan. Sebagai telah dimaklumi bersama bahwa segala pekerjaan yang dilakukan dengan tenang akan mencapai hasil yang memuaskan. Orang tenang tidak akan terikat oleh perasaan suka duka dan mereka dapat memusatkan perhatian dalam suatu pekerjaan yang sedang dilakukan. Mereka mempunyai keyakinan bahwa pekerjaan yang dihadapi adalah kewajibannya dan harus diselesaikan dikerjakan. Tentunya orang yang bijaksana akan mengerjakan kewajibannya dengan tulus iklas dengan penuh kesadaran dan pengorbanan.

Atas dasar kewajibannya Sri Krisna menyadarkan Arjuna dalam keragu-raguan supaya bangkit dan menunaikan tugas kewajibannya berperang sebagai seorang ksatrya, dalam menegakkan kebenaran dan keadilan. Lebih lanjut Krisna menjelaskan tentang kebenaran dan keadilan seperti tercermin pada kitab suci Bhagawad Gita bab II sloka 16, 17 dan 18 berikut ini.

Na sato widyate bhawo

na bhawo widyate saah

ubhayor pi dristo ntaswa

anayos tatwa darsibhih

awinasi tu tad widhi

yena sarwam idam tatam

winasam awyayasya sya

na kascit kartu arthati

antawata ime deha

nityasyo ktah saririnah

anasino prameyasya

tasmad ydhyasya bharata

\section{Terjemahannya :}

Apa yang tiada tidak pernah akan ada yang ada, takkan berhenti ada keduanya hanya dapat dimengerti oleh orang yang tahu kebenarannya. 
Dengan mengerti hal ini semua, berarti tahu kepada yang kekal, serta tidak seorangpun yang mampu menghancurkan terhadap sesuatu yang kekal.

Adapun yang abadi itu (atman) adalah tidak dapat berubah, tak dapat diukur, sedangkan jasmani itu mempunyai saat berakhirnya maka itu wahai Bharata (Arjuna) bertempurlah (Pendit, 1996:45-47).

Dalam kutipan sloka di atas disebutkan oleh Sri Krisna bahwa sesuatu yang nyata adalah tidak ada dan sesuatu yang tidak nyata tidak ada juga, dengan demikian juga tersirat apa yang tiada takkan pernah akan ada, apa yang ada takkan berhenti ada Apakah yang sebenarnya tersimpul dalam ucapan itu ? Untuk mencari kesimpulan yang terpendam dalam filsafat itu memerlukan suatu perenungan yang lebih mendalam. Untuk itu akan diusahakan memberikan penjelasan sebatas kemampuan yang ada. Sesuatu yang nyata seperti meja, baju, air dan lain-lainnya benda-benda itu menurut filsafat Hindu adalah tidak ada atau maya, karena benda-benda ini mengalami lahir, tumbuh dan mati, namun yang ada (kekal) dan ada secara mutlak yaitu Tuhan. Maka itulah tujuan hidup yang dalam filsafat Hindu adalah mencari kebenaran (Tuhan) yang bersifat kekal abadi. Dengan mendalami serta menghayati ajaran yang amat rahasia ini memberikan suatu tuntunan untuk berbuat yang benar, cinta kepada kebajikan dan kewajiban suci, tidak terikat oleh senang dan susahnya materi dunia ini. Maka dari itu kita harus berusaha untuk ingat dengan kewajiban masing- masing sesuai dengan dharma untuk menegakkan keadilan dan kebenaran, sehingga tujuan hidup akan tercapai.

Untuk itu Sri Krisna lebih lanjut menjelaskan tentang kewajiban seorang ksatrya. Hal ini tercermin dalam kitab suci Bhagawad Gita bab II, sloka37 berikut ini.

Hato wa prapsyasi swargaam

jitwa wa bhoksyase mahim

tasmat utisttha kaunteya

yudhaya kritanischayah

Terjemahannya :

Andai .Andai kata Engkau tewas dalam pertempuran, Engkau akan mendapat sorga, ataupun jika engkau menang, engkau akan menikmati kebahagiaan dunia, maka itu bangkitlah Kunti Putra (Arjuna) sadarlah, majulah, dan bertempurlah (Pendit, 1996 : 57).

Sebagai seorang ksatrya hendaknya benar-benar insyaf untuk berdarma bhakti dan menunaikan kewajiban serta pengabdian, melepaskan diri dari ikatan-ikatan senang susah yang pribadi. Dengan demikian tidak akan raguragu lagi menerjunkan diri dalam bhakti, dengan melepaskan ikatan dosa yakni sifal ragu-ragu dan enggan berkarma. Sebagai seorang ksatrya yang demikian ini, jika gugur dalam tugas di medan perang akan mendapatkan sorga dan jika menang masih hidup akan menikmati kebahagiaan dan menyandang tanda jasa. Tetapi apabila sebaliknya seorang ksatriya yang ingkar akan kewajibannya, 
maka ia akan dicela oleh musuhnya, dihina, dicaci maki dan dianggap. Jika demikian inilah kehidupan yang ternista disebabkan karena lalai akan tugas dan kewajibannya.

Demikianlah secara singkat ajaran Sri Krisna kepada Arjuna yang berupa ajaran filsafat Samkhya Yoga, merupakan pengetahuan tentang atma dan sthula sarira atau purusa dan prakerti yang merupakan dualisme dalam konsepsi samkhya. Oleh Sri Krisna dilanjutkan dengan konsep Karma Yoga, yang merupakan ajaran spiritual berdasarkan karma untuk mencapai kebenaran. Ajaran Samkhya dan Yoga amat besar pengaruhnya terhadap ajaran tattwa di Bali, hal ini dapat kita jumpai dalam Aji Samkhya, dengan konsepsi dualistisnya yaitu purusa dan prakerti yang dianggap sebagai awai dari segala-galanya. Sedangkan ajaran yoga menambahkan bahwa purusa dan prakerti adalah bersumber kepada Iswara, sehingga dengan demikian lebih dikenai dengan konsepsi Samkhya Yoga dengan sifat ajarannya monodualistis.

\section{PENUTUP}

Dharma Yudha Karma adalah suatu ajaran agama Hindu yang berarti suatu kerja atau perjuangan hidup yang disimbulkan dalam bentuk perang yang dijiwai atau berlandaskan atas ajaran Dharma (agama). Dharma Yudha Karma merupakan ajaran yang memberikan dorongan kepada umat manusia untuk berkerja, berjuang tanpa terikat akan hasil dari memandang kerja merupakan kewajiban yang harus dilaksanakan. Dharma Yudha Karma mengandung suatu pendidikan pembinaan moral untuk cinta pada kebenaran, cinta pada keadilan, cinta pada kejujuran dan cinta pada keikhlasan. K o n s e p s i ajaran Dharma Yudha Karma, yang terkandung dalam kitab suci Bhagawad Gita memberikan suatu pendidikan disiplin diri menghilangkan sifat enggan dan ragu-ragu dalam menghadapi masalah agar menjadi manusia yang cekatan, tegas dan berani membela kebenaran. Dharma Yudha Karma adalah suatu konsepsi filosofis dari ajaran agama Hindu yang dituangkan dalam ajaran Karma Marga dan Bhakti Marga, yang prinsipnya selalu menekankan agar umat Hindu selalu yakin kebenaran mutlak hanyalah Tuhan itu sendiri. Sedangkan apa yang tampak (kita lihat) hanyalah sementara (maya) sifatnya yang tak dapat memberi kebahagiaan yang kekal sehingga umat Hindu lebih diarahkan untuk mencari yang tak tampak (Tuhan) dengan jalan karma dan selalu berbhakti tiada henti-hentinya kepadanya.

\section{DAFTAR PUSTAKA}
Cudamani, 1991. Pengantar Agama Hindu (Untuk Perguruan tinggi). Jakarta : Hanuman sakti.

Darmayasa, 2012/2013. Bhagavad Gita (Nyanyian Tuhan). Denpasar.

Kurniawan, I Nyoman. 2013. Samsara Perjalan Sang Jiwa Dalam Kehidupan Dan Kematian. Surabaya : Paramitha 
Lontar Wraspati Tattwa. Denpasar : Koleksi Pendit, 1996. Bhagawad Gita. Jakarta : Hanoman Pusdok Kebudayaan Pemda Tingkat I Bali.

Mantra, 1993. Tata Susila Hindu Dharma. Jakarta : Hanoman Sakti.

Maswinara, I Wayan. 2003. Srimad Bhagawad Gita. Surabaya : Paramitha

Nala, I Gusti Ngurah. 1991. Murdha Agama Hindu. Denpasar : Upada Sastra

Pudja, G.1999. Bhagawad Gita (pancamo veda). Surabaya : PT Paramita.

Prabhupada, Sri Srimad A.C. Bhaktivedanta Swami. 2006. Bhagawad Gita Menurut Aslinya. Denpasar : Hanoman Sakti.

Pudja, 1997/1978. Manawa Dharma Sastra (Manu Dharma Sastra/Weda Smerti).Jakarta.

Pudja, 1983. Bhagawad Gita. Jakarta : Penelitian dan Pengembangan Kitab Weda.

Pudja, 2003. Bhagawad Gita (Pancama Weda). Jakarta : PT. Pustaka Mitra Jaya.
Sakti.

Poedjawijatna, 1990. Etika Filsafat Tingkah Laku. Jakarta : Rineka Cipta.

Sri Swami Siwananda, 1993. Intisari Ajaran Hindu. Surabaya : PT. Paramita.

Suhardana, Komang. 2010. Moksa Brahman Atman Aikyam. Surabaya : Paramitha

Ranganathananda, Swami. 2000. Pesan Universal Bhagawad Gita. Media Hindu

Titib, I Made, 1996. Weda Sabda Suci Pedoman Praktis kehidupan. Surabaya : Paramita. 